\title{
Novel pre-treatment of zeolite materials for the removal of sodium ions: potential materials for coal seam gas co-produced wastewater
}

\author{
Oscar Santiago ${ }^{1}$, Kerry Walsh', Ben Kele ${ }^{1,2}$, Edward Gardner ${ }^{1}$ and James Chapman ${ }^{*^{*}}$
}

${ }^{*}$ Correspondence:

j.chapman@cqu.edu.au

${ }^{1}$ School of Medical and Applied Sciences,

CQUniversity, Rockhampton, QLD 4701, Australia

Full list of author information is available at the end of the article

\begin{abstract}
Coal seam gas (CSG) is the extraction of methane gas that is desorbed from the coal seam and brought to the surface using a dewatering and depressurisation process within the saturated coalbed. The extracted water is often referred to as co-produced CSG water. In this study, co-produced water from the coal seam of the Bowen Basin (QLD, Australia) was characterised by high concentration levels of $\mathrm{Na}^{+}(1156 \mathrm{mg} / \mathrm{L})$, low concentrations of $\mathrm{Ca}^{2+}(28.3 \mathrm{mg} / \mathrm{L})$ and $\mathrm{Mg}^{2+}(5.6 \mathrm{mg} / \mathrm{L})$, high levels of salinity, which are expected to cause various environmental problems if released to land or waters. The potential treatment of co-produced water using locally sourced natural ion exchange (zeolite) material was assessed. The zeolite material was characterized for elemental composition and crystal structure. Natural, untreated zeolite demonstrated a capacity to adsorb $\mathrm{Na}^{+}$ions of $16.16 \mathrm{mEq} / 100 \mathrm{~g}$, while a treated zeolite using $\mathrm{NH}_{4}{ }^{+}$ using a $1.0 \mathrm{M}$ ammonium acetate $\left(\mathrm{NH}_{4} \mathrm{C}_{2} \mathrm{H}_{3} \mathrm{O}_{2}\right)$ solution demonstrated an improved $136 \% \mathrm{Na}^{+}$capacity value of $38.28 \mathrm{mEq} / 100 \mathrm{~g}$ after $720 \mathrm{~min}$ of adsorption time. The theoretical exchange capacity of the natural zeolite was found to be $154 \mathrm{mEq} / 100 \mathrm{~g}$. Reaction kinetics and diffusion models were used to determine the kinetic and diffusion parameters. Treated zeolite using a $\mathrm{NH}_{4}{ }^{+}$pre-treatment represents an effective treatment to reduce $\mathrm{Na}^{+}$concentration in coal seam gas co-produced waters, supported by the measured and modelled kinetic rates and capacity.
\end{abstract}

Keywords: Coal seam gas (CSG), lon exchange, CSG water management, Water treatment, Saline water, Zeolite

\section{Background}

Coal seam gas (CSG), also known as coal-bed methane (CBM) is gas adsorbed onto underground coal seams and is composed mainly of methane, originating from biogenic, thermogenic and metamorphic sources (Nghiem et al. 2011). In Australia, large CSG deposits are found in Bowen and Surat coal basins of QLD (Baker and Slater 2008). The production of CSG is achieved by allowing methane gas to desorb from the coal seam and flow to the surface, which results in large volumes of co-produced water from the saturated coal seam. In addition, CSG recovery results in virtually no negative impact on future extractive mining of the coal deposits (Baker and Slater 2008). The large volumes 
of co-produced water in the CSG operation presents a significant challenge to manage, especially for future use. It is estimated that over the next 25 years the CSG industry will produce an average volume of 25 gigalitres (GL) of water per year in QLD's gas fields (Hamawand et al. 2013).

CSG co-produced water has a geochemical signature characterised often by high levels of salinity, high concentrations of sodium ions and dissolved trace metals that cause various environmental problems if released to land or waters without treatment or incorrect management (Jackson and Reddy 2007; Jones et al. 2014; Regan et al. 2013). On the other hand, CSG co-produced water has the potential to be used for these beneficial usages including: irrigation, feedlots watering, aquaculture and agricultural activities (Wang et al. 2012). However, the challenge, is that CSG water usually requires treatment or amendment prior to its beneficial usage.

CSG water quality varies between coal bed depths, coal formation profiles and basin types (Baker and Slater 2008). Typically, CSG water has a substantial total dissolved solid (TDS) value, with an elevated concentration of $\mathrm{Na}^{+}$ions, but a low concentration of $\mathrm{Ca}^{2+}$ and $\mathrm{Mg}^{2+}$ (Taulis and Milke 2007). The primary concerns for using CSG coproduced water for irrigation include: high concentration of dissolved salts (that limit plant growth via osmotic drought effects) and an excessive $\mathrm{Na}^{+}$ion concentration (that can cause soil dispersion due to low $\mathrm{Ca}^{2+}$ and $\mathrm{Mg}^{2+}$ concentration) thereby reducing soil tilth and soil water infiltration rates (Rengasamy and Marchuk 2011). Therefore, treatment or amendment options for CSG waters often consider the reduction of $\mathrm{Na}^{+}$ions.

Some of the more commonly used water treatment technologies used to manage CSG water are (Nghiem et al. 2011):

- desalinisation process using membrane technology;

- distillation;

- electrodialysis and;

- ion exchange resins.

In Australia, the commonly used reverse osmosis (RO) methods generate large volumes of concentrated water (brine) that require additional disposal, resulting in increased capital and operating costs for a CSG well field. Furthermore, the membranes used in the RO system often lack of resistance to fouling (Chapman and Regan 2011), often reducing efficiency and driving up cost; thus making the overall cost for managing CSG waters and gas production unprofitable (Hamawand et al. 2013; Nghiem et al. 2011). Therefore, there is a significant need in the CSG industry for a cost-effective alternative treatment that reduces $\mathrm{Na}^{+}$concentrations on CSG water prior to any beneficial usage.

Natural exchangers such as zeolites are widely used in the treatment of industrial wastewaters for removing contaminants such as $\mathrm{Cu}^{2+}, \mathrm{Fe}^{3+}, \mathrm{Cr}^{3+}, \mathrm{Ni}^{2+}, \mathrm{Cd}^{2+}, \mathrm{Pb}^{2+}, \mathrm{NH}_{4}^{+}$ amongst other metals (Argun 2008; Bektaş and Kara 2004; Cincotti et al. 2001; Inglezakis et al. 2002; Nguyen and Tanner 1998; Stylianou et al. 2007; Weatherley and Miladinovic 2004). Some authors have also attempted to treat CSG produced waters using natural zeolites (Wang et al. 2012; Zhao et al. 2008, 2009). Natural zeolites are reported to remove sodium ions from solution by replacing them with calcium, thereby reducing $\mathrm{Na}^{+}$ 
concentration. Zhao et al. (2009) suggest that natural exchangers could become a suitable cost effective technology for the treatment of high $\mathrm{Na}^{+}$of CSG co-produced waters.

Zeolite minerals are natural ion exchangers with a crystalline, porous, three-dimensional aluminosilicate alkali and alkaline metal structures capable of exchanging cations (Pabalan and Bertetti 2001). The zeolite structure is based on a tetrahedral (SiAl) $\mathrm{O}_{4}$ framework with four oxygen adjacent shared. The negative surplus charge of the zeolites originates from the substitution of $\mathrm{Si}^{4+}$ with $\mathrm{Al}^{3+}$, which is then balanced with exchangeable cations such as sodium $\left(\mathrm{Na}^{+}\right)$, potassium $\left(\mathrm{K}^{+}\right)$, calcium $\left(\mathrm{Ca}^{2+}\right)$ or magnesium $\left(\mathrm{Mg}^{2+}\right)$ (Townsend 1986). Natural zeolites have a high cation exchange capacity and selectivity due to their high porosity and sieving properties (Zhao et al. 2008). Clinoptilolite and mordenite zeolite materials have a theoretical cation exchange capacity (CEC) of $202 \mathrm{mEq} / 100 \mathrm{~g}$ (Pabalan and Bertetti 2001) (Fig. 1).

Natural ion exchangers can also be treated from their initial or natural state by single or combined chemical adjustment using acids, bases and inorganic salts (Babak et al. 2013; Günay et al. 2007; Inglezakis et al. 2001; Wang et al. 2012). These chemical treatments result in cation migration from within the crystal framework, and cation replacement by the newly introduced cation species. The chemical treatment removes ions on the exchanger for those that are more removable under ion exchange conditions. Treatment typically increases the presence of one cation on the exchanger converting it into a near homoionic condition (Inglezakis et al. 2004; Semmens and Martin 1988). The homoionic form of the exchanger can improve the effective exchange capacity, enhancing the ion exchange process (Inglezakis et al. 2001; Inglezakis and Zorpas 2012; Vassileva and Voikova 2009; Wang and Peng 2010). Treatment with inorganic salts is recognised as an effective technique to improve natural ion exchangers overall cation exchange capacity (CEC) for water treatment applications.

The present study aims at quantifying the characteristics and ability of Australian natural and treated zeolite for the removal of sodium ions present in co-produced coal seam gas water, as well as the efficacy of zeolite chemical treatment on the adsorption of $\mathrm{Na}^{+}$rate and effective exchange capacity. This work provides an effective and practical application for zeolite on the treatment of CSG waters for Australia and elsewhere.

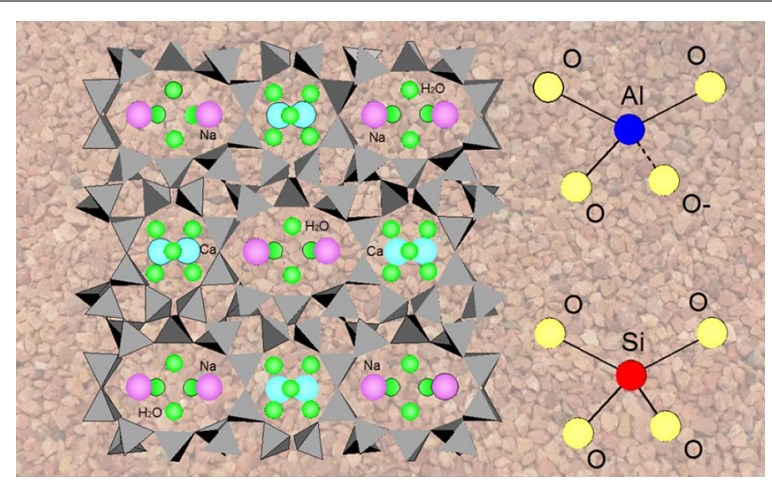

Fig. 1 Zeolite three dimensional framework of $(\mathrm{SiAl}) \mathrm{O}_{4}$ tetrahedral where all oxygen ions of the tetrahedron are shared with adjacent tetrahedral structures (Inglezakis and Zorpas 2012). The presence of $\mathrm{Al}^{\mathrm{l}+}$ in place of $\mathrm{Si}^{4+}$ in the structure gives a negative charge that is balanced by cations. Zeolite material used in this study 


\section{Methods}

\section{Material characterisation}

The zeolite used in this study had been identified for its suitability in CSG water treatment by another research project being conducted at CQUniversity, Australia (Kele 2015, Unpublished Dissertation). This research project first identified the sodium exchange properties of natural zeolites at a recycled water test site in 2003 (Kele 2005). A variety of volcanic media was tested for sodium exchange properties with CSG water from wells in the Bowen and Surat basins (Kele 2015). The zeolite media in this paper had the best results for sodium reduction in the Bowen basin CSG water (Kele 2015). Samples were crushed and sieved to a size range of 0.6$0.3 \mathrm{~mm}$ for subsequent batch type experiments. The natural zeolite was characterised using X-ray fluorescence (XRF) using an ARL SMS-Omega XRF instrument in order to determine its elemental composition, zeolite sample was ground to a pressed pellet for analysis. Characterisation of the zeolite crystalline structure was examined on a XRD PANalytical X'Pert Pro diffractometer (40 kW and $40 \mathrm{~mA}$, angular scanning range $5-80^{\circ}$, and angular speed $2 \theta / \mathrm{s}$ ). Mineral identification was undertaken using X'Pert HighScore search/match software, whilst quantitative analysis of the XRD data was performed using SIROQUANT ${ }^{\mathrm{TM}} \mathrm{V} 3$. The surface area of the natural zeolite was measured using the $\mathrm{N}_{2}$ gas adsorption method at $-196{ }^{\circ} \mathrm{C}$ on the ASAP2390a from Micrometrics Instrument Corporation, and BET and single point methods were used to determine the specific surface area. Reported mineral characteristics of the material correspond to the mean of two replicates, which did not vary by more than $5 \%$.

\section{Water samples}

CSG co-produced water samples were collected from a CSG water treatment facility in a gas field in the southern Bowen basin in QLD, Australia, at monthly intervals over a 14 month period. Chemical analyses of the CSG water samples were conducted at Lanfax Laboratories, a laboratory that has National Association of Testing Authorities (NATA) accreditation. Metal concentrations of experimental samples were analysed using an Agilent 720 Inductively Coupled Plasma Optical Emission Spectrometer (ICP-OES), every element was analysed in triplicate for every sample and used by the instrument to estimate relative standard deviation (RSD) automatically $(<5 \%)$. ICP multi-element standard solution Merck® ${ }^{\circ}$ was used for calibration purposes. Stock metal standard solutions and chemical reagents used were analytical grade (Chem-Supply). Stock solutions were prepared with Ultrapure Academic Milli-Q water (18.0 $\Omega$ ). A portable multi-parameter sympHony (VWR) meter with ThermoFisher probes and calibrations solutions were used to determine conductivity (salinity) and $\mathrm{pH}$.

\section{Batch kinetic experiments and material treatment}

The kinetic adsorption of $\mathrm{Na}^{+}$ions was measured for natural and four chemical treated zeolite samples. Natural zeolite was washed with Milli-Q water to remove dust and material impurities, then oven dried at $105^{\circ} \mathrm{C}$ for $24 \mathrm{~h}$ and stored in sealed HDPE containers. A $40 \mathrm{~g}$ sample of natural zeolite was treated with $800 \mathrm{~mL}$ of either $1 \mathrm{M}$ calcium chloride $\left(\mathrm{CaCl}_{2}\right), 1 \mathrm{M}$ hydrochloric acid $(\mathrm{HCl}), 1 \mathrm{M}$ potassium chloride $(\mathrm{KCl})$, and $1 \mathrm{M}$ ammonium acetate $\left(\mathrm{NH}_{4} \mathrm{C}_{2} \mathrm{H}_{3} \mathrm{O}_{2}\right)$. In each case, the treatment involved shaking the zeolite samples in contact with the treatment solution for $24 \mathrm{~h}$ (incubator Bioline 8500 at $25{ }^{\circ} \mathrm{C}$ ), rinsing with Milli-Q water (until free of $\mathrm{Cl}^{-}$ions, using silver nitrate $\left(\mathrm{AgNO}_{3}\right)$ 
test and controlling washing solution salinity), filtration from supernatant (using a mixed cellulose ester membrane filter of $0.45 \mu \mathrm{m}$, Advantec ${ }^{\circledR}$ ), and drying at $105^{\circ} \mathrm{C}$ for $24 \mathrm{~h}$.

Batch type kinetic experiments were conducted using $30 \mathrm{~g}$ of either natural or treated zeolite material and $600 \mathrm{~mL}$ of $0.1 \mathrm{M}$ sodium chloride $(\mathrm{NaCl})$ in a $1000 \mathrm{~mL}$ HDPE container placed on an orbital shaker at $300 \mathrm{rpm}$ at a constant temperature of $25{ }^{\circ} \mathrm{C}$ for 720 min (incubator Bioline 8500 at $25^{\circ} \mathrm{C}$ ) (Lehto and Harjula 1995). Aliquots of $1 \mathrm{~mL}$ were withdrawn from each container at intervals, where the total sample volume was $<2 \%$ of the total volume of the solution (Inglezakis et al. 2004). Aliquots were diluted with $\mathrm{HNO}_{3}$ at $2 \%$ for analytical ICP-OES analysis to determine total metal ion concentration. To ensure experimental accuracy, experiments were repeated following the same methods and conditions.

\section{Adsorption kinetics and diffusion modelling}

The concentration of $\mathrm{Na}^{+}$ions transferred to the solid phase of the zeolite, $q$ (mEq/100 g), was calculated using Eq. 1:

$$
q=\left(C_{0}-C_{t}\right) \times \frac{v}{m}
$$

where $C_{0}$ and $C_{t}$ are the amount of initial and retained $\mathrm{Na}^{+}$ions in the solution at time $t$ $(\mathrm{mEq} / \mathrm{L})$, respectively, $v$ is the solution volume $(\mathrm{mL})$ and $m$ is the weight of adsorbent $(\mathrm{g})$ (Argun 2008; Kocaoba et al. 2007; Kumar and Jain 2013). Experimental results demonstrate chemical kinetic behaviour describing reaction pathway, time to reach equilibrium and rate of reaction. Determination of kinetic parameters is complex due to the heterogeneity of the adsorption mechanisms within the system (Bektaş and Kara 2004; Oren and Kaya 2006).

The adsorption kinetic models have more than two adjustable parameters that may not be fitted to experimental data by linear regression, requiring a nonlinear least square analysis. For that reason, the sum of error squared (SSE) was used as the minimisation procedure to solve kinetic equations between experimental and predicted data using Matlab $^{\circledR}$ R2012b by MathWorks ${ }^{\circledR}$. Nonetheless, linear fitting was also used and the coefficient of determination $\left(R^{2}\right)$ was calculated using the experimental and predicted data (Bektaş and Kara 2004; Du et al. 2005; Günay et al. 2007). The experimental data was fitted with reaction kinetic models (Table 1) and diffusion models (Table 2) to estimate the adsorption kinetics parameters of the ion exchange system dynamics and diffusion processes under the experimental conditions.

The pseudo-first order reaction kinetic model is based on a reversible reaction with an equilibrium state being reached on both liquid and solid phases (Argun 2008; Babak et al. 2013) and it is expressed in Eq. 2. The pseudo-second order kinetic equation is based on

Table 1 Reaction kinetic models

\begin{tabular}{lllll}
\hline Model & Non-linear equation & Linear equation & \multicolumn{2}{l}{ Model parameters } \\
\hline Pseudo-first order & $q_{t}=q_{e}\left(1-e^{-k_{1} t}\right)$ & $\log \left(q_{e}-q_{t}\right)=\log \left(q_{e}\right)-k_{1} t$ & $q_{e}, k_{1}$ & Equation 2 \\
Pseudo-second order & $q_{t}=\frac{q_{e}^{2} k_{2} t}{\left(1+q_{e} k_{2} t\right)}$ & $\frac{t}{q_{t}}=\frac{1}{k_{2} q_{e}^{2}}+\left(\frac{1}{q_{e}}\right) t$ & $q_{e}, k_{2}$ & Equation 3 \\
& $q_{t}=\left(\frac{1}{b}\right) \ln (a b t+1)$ & $q_{t}=\frac{\ln (a b)}{b}+\frac{\ln (t)}{b}$ & $a, b$ & Equation 4 \\
\hline
\end{tabular}


Table 2 Diffusion models

\begin{tabular}{llll}
\hline Model & Non-linear equation & Model parameters & \\
\hline Intra-particle diffusion & $q_{t}=k_{i} t^{1 / 2}+C$ & $k_{i} C$ & Equation 5 \\
Film diffusion & $D_{f}=0.23 \frac{r_{0} \delta q_{e}}{t_{1 / 2}}$ & $D_{f}$ & Equation 6 \\
Pore diffusion & $D_{p}=0.03 \frac{r_{0}^{2}}{t_{1 / 2}}$ & $D_{p}$ & Equation 7 \\
\hline
\end{tabular}

the adsorption equilibrium capacity of the solid phase to uptake ions and whose form is expressed in the form of Eq. 3 (Bektaş and Kara 2004; Kumar and Jain 2013). The Elovich equation is widely used in adsorption kinetic studies to describe the chemical adsorption of ions and is written in the form of Eq. 4 (Cincotti et al. 2001; Du et al. 2005).

In Table $1, q_{t}(\mathrm{mEq} / 100 \mathrm{~g})$ is the amount of $\mathrm{Na}^{+}$ions adsorbed at time $t(\mathrm{~min})$, $q_{e}(\mathrm{mEq} / 100 \mathrm{~g})$ is equilibrium solid phase concentration, $k_{1}$ is first order rate constant for adsorption $\left(\mathrm{min}^{-1}\right), k_{2}$ is second order rate constant for adsorption $\left(\mathrm{min}^{-1}\right), a$ is the initial adsorption rate $(\mathrm{mEq} / 100 \mathrm{~g} \mathrm{~min})$ and $b$ is the Elovich constant $(\mathrm{mEq} / 100 \mathrm{~g})$.

Kinetics reaction models can describe the adsorption equilibrium, however, they cannot identify the diffusion mechanism of the adsorption processes that is taken place. Therefore, kinetic results can be analysed by using the intraparticle, film and pore diffusion models. Diffusion processes occur when the liquid forms a film layer surrounding the zeolite particle. When the film layer is formed, external diffusion or film diffusion occurs on the surface of the particle. When the liquid reaches the internal framework of the zeolite particle, it is considered an intraparticle diffusion or pore diffusion process (Babak et al. 2013; Karthikeyan et al. 2010).

The examination of ion exchange system kinetics can reveal the adsorption mechanism underlining the sorption processes which can be the product of film diffusion, pore diffusion or both. These two processes provide insight into whether diffusion is controlled by ion exchange or not. Ion exchange kinetics are considered to be a mass transfer process from the liquid phase to the zeolite to determine the time lapsed until equilibrium. When solution with $\mathrm{Na}^{+}$ions is in contact with the natural zeolite, transport of ions occurs from liquid to solid phase through diffusion processes. The rate of adsorption is often limited by the diffusion process on the external surface of the zeolite particle and within the porous sites available in the zeolite (Argun 2008). Equations 5, 6 and 7 (Table 2), determine the intra-particle, film and pore diffusion coefficients of the system.

Model parameters in Table 2, $k_{i}$ is the intraparticle diffusion rate constant ( $\mathrm{mEq} / 100 \mathrm{~g} \mathrm{~min}$ ), $C$ is the constant related with the boundary layer (Huang et al. 2010), $D_{f}$ is the film diffusion coefficient $\left(\mathrm{cm}^{2} / \mathrm{s}\right), r_{0}$ is the radius of the particle $(\mathrm{cm}), \delta$ is the film thickness (cm), $t_{1 / 2}$ is the half time for the ion exchange process (min) and $D_{p}$ is the pore diffusion coefficient ( $\mathrm{cm}^{2} / \mathrm{s}$ ) (Argun 2008; Karthikeyan et al. 2010).

\section{Effective sodium adsorption capacity of natural and treated zeolite material}

Effective adsorption capacity is the amount of sodium ions that can be retained in a specific mass of zeolite material and that are exchangeable under specific experimental conditions (Inglezakis 2005). Capacity studies were conducted on batch mode experiment 
using $30 \mathrm{~g}$ of natural and chemical treated zeolite in a $1000 \mathrm{~mL}$ HDPE container with $600 \mathrm{~mL}$ of $\mathrm{NaCl}$ at $0.1 \mathrm{M}$ for 5 days until no further $\mathrm{Na}^{+}$uptake from the zeolite was observed. To ensure experimental accuracy, experiments were repeated using identical conditions.

\section{Results and discussion}

Material characterisation

The theoretical cation exchange capacity (TEC) of the natural zeolite resulted from the sum of exchangeable cations such as $\mathrm{Na}^{+}, \mathrm{K}^{+}, \mathrm{Ca}^{2+}$ and $\mathrm{Mg}^{2+}$ determined by the chemical composition, in Table 3, was found to be $154 \mathrm{mEq} / 100 \mathrm{~g}$. Bektaş and Kara (2004) and Inglezakis et al. (2002) found that Turkish and Greek clinoptilolite have a TEC of 250 and $264 \mathrm{mEq} / 100 \mathrm{~g}$, respectively. The Si:Al ratio for the natural zeolite is $5.29(\mathrm{~mol} / \mathrm{mol})$ and the $\left(\mathrm{Na}^{+}+\mathrm{K}^{+}\right) / \mathrm{Ca}^{2+}$ ratio is $1.61(\mathrm{~mol} / \mathrm{mol})$. The $\mathrm{Si}: \mathrm{Al}$ ratio between 4 and 5.5 and are generally characteristic of clinoptilolite zeolite material (Alberti et al. 1997).

The qualitative and quantitative XRD analysis for the mineral crystalline phases of the natural zeolite material determined that it is made clinoptilolite (41\%), mordenite (29\%) and quatrz (30\%). Both clinoptilolite and mordenite made $70 \%$ of the natural zeolite material. The surface area of the natural material measured using the single-point and Brauner-Emmett-Teller (BET) methods with nitrogen gas was 4.47 and $4.50 \mathrm{~m}^{2} / \mathrm{g}$ respectively. Zeolite samples from Vassileva and Voikova (2009) and Bektaş and Kara (2004) were composed of $80 \%$ clinoptilolite and had surface areas of 26 and $15.36 \mathrm{~m}^{2} / \mathrm{g}$, correspondenly. Furthermore, small amounts of impurities mainly quatz and clays block channels decreasing the estimation of the surface area (Sprynskyy et al. 2010). Therefore, surface are these channels may have a small contribution.

\section{Characterisation of co-produced coal seam gas water}

CSG co-produced water samples were collected from a CSG water treatment facility in the southern part of the Bowen Basin (QLD). The chemical composition of 14 CSG water samples taken at monthly basis are shown in Table 4 .

Table 3 Chemical composition of natural zeolite material used in the present study

\begin{tabular}{lccccccccccccc}
\hline Element & $\mathrm{Na}_{2} \mathbf{O}$ & $\mathbf{M g O}$ & $\mathbf{A l}_{2} \mathbf{O}_{3}$ & $\mathbf{S i O}_{2}$ & $\mathbf{P}_{2} \mathbf{O}_{5}{ }^{\mathbf{a}}$ & $\mathbf{S O}_{2}{ }^{\mathbf{a}}$ & $\mathbf{K}_{2} \mathbf{O}$ & $\mathbf{C a O}$ & $\mathrm{TiO}_{2}$ & $\mathbf{M n O}$ & $\mathrm{Fe}_{2} \mathbf{O}_{3}$ & $\mathbf{B a O}$ & $\mathbf{L O I}^{\mathbf{b}}$ \\
\hline$\%(\mathrm{w} / \mathrm{W})$ & 1.83 & 0.88 & 11.7 & 72.84 & 0.04 & 0.006 & 1.08 & 2.85 & 0.18 & 0.03 & 1.34 & 0.13 & 7.14 \\
\hline
\end{tabular}

a Detection limit (0.001)

b LOI determined gravimetrically

Table 4 Chemical analysis of CSG water

\begin{tabular}{lrrrrrlll}
\hline & $\mathrm{Na}^{+}$ & $\mathrm{Ca}^{2+}$ & $\mathbf{M g}^{2+}$ & $\mathrm{Cl}^{-}$ & $\mathrm{HCO}_{3}^{-}$ & $\begin{array}{l}\mathrm{SAR} \\
\left(\mathbf{m E q} / \mathbf{m E q}^{\mathbf{2} 2}\right)\end{array}$ & $\mathbf{E C}(\mathbf{d S} / \mathbf{c m})$ & $\mathbf{p H}$ \\
\hline $\bar{X}$ & & & & & & & & \\
$(\mathrm{mg} / \mathrm{L})$ & 1156.4 & 28.3 & 5.6 & 1993 & 618.1 & 104 & 6.02 & 8.34 \\
$(\mathrm{mEq} / \mathrm{L})$ & 50.3 & 0.35 & 0.12 & 56.2 & 10.1 & & & \\
$\sigma$ & & & & & & & 1.48 & 0.58 \\
$(\mathrm{mg} / \mathrm{L})$ & 241.6 & 38.5 & 2.8 & 759.9 & 140.7 & 20 & & \\
$(\mathrm{mEq} / \mathrm{L})$ & 10.5 & 0.4 & 0.06 & 21.4 & 2.3 & & \\
\hline
\end{tabular}


The CSG water chemical composition was dominated by sodium ions, which are 40 times more concentrated when concentrations of $\mathrm{Ca}^{2+}$ and $\mathrm{Mg}^{2+}$ are compared. The electrical conductivity value greater than $6 \mathrm{dS} / \mathrm{cm}, \mathrm{pH}$ of 8.34, and the CSG water chemical characterisation, co-produced water from Bowen Basin is classified as brackish alkaline $\mathrm{Na}^{+}-\mathrm{Cl}^{-}-\mathrm{HCO}_{3}{ }^{-}$water. $\mathrm{CSG}$ water chemical composition is consistent with values reported by Hamawand et al. (2013) and Kinnon et al. (2010) for CSG waters from the Bowen Basin, which presented an absence of sulphate, low concentrations of $\mathrm{Ca}^{2+}$ and $\mathrm{Mg}^{2+}$ and high concentrations of $\mathrm{Na}^{+}, \mathrm{Cl}^{-}$and $\mathrm{HCO}_{3}{ }^{-}$ions.

\section{$\mathrm{Na}^{+}$adsorption kinetics}

In order to determine the adsorption kinetics of $\mathrm{Na}^{+}$onto natural and treated zeolite material, batch type experiments were conducted. Pseudo-first, pseudo-second and Elovich kinetic models were fitted to the experimental data to determine kinetic parameters. Diffusion model and coefficients were determine using intra-particle, film and pore diffusion from experimental data.

\section{Adsorption kinetics modelling of $\mathrm{Na}^{+}$using zeolite material}

The removal of $\mathrm{Na}^{+}$ions by ion exchange and adsorption on to zeolite material increased with time and plateau attaining a maximum value as shown by the experimental data in Fig. 2.

Evidently, the adsorption process consisted of two main reaction stages; a fast adsorption followed by a slow adsorption. The fast $\mathrm{Na}^{+}$adsorption process by the natural and treated zeolite material occurred among the $100 \mathrm{~min}$. The rapid process is then followed by a slow adsorption that gradually decreased as contact time increased. After $480 \mathrm{~min}$, the $\mathrm{Na}^{+}$adsorption process almost reached the maximum adsorption capacity under the experimental conditions for natural and treated zeolite material. A similar behaviour was observed and reported by Argun (2008) and Bektaş and Kara (2004) for natural and treated clinoptilolite.

The experimental data was used to determine kinetic constants and predict the kinetic curves of the ion exchange system using pseudo-first, pseudo-second order and Elovich as shown in Fig. 2. Table 5 reports the values obtained from experimental and modelled $\mathrm{Na}^{+}$adsorption capacity of zeolite material, the adsorption rate, capacity, SSE and $R^{2}$ found between the experimental and modelled data.

The experimental adsorption capacity of natural zeolite form after 720 min was $q_{e}=$ $16.16 \mathrm{mEq} / 100 \mathrm{~g}$, which is higher that the capacity determined by the kinetic models used (Fig. 2a-c). The pseudo-second model, which is demonstrated to be a model that best describes the $\mathrm{Na}^{+}$adsorption process for natural zeolite under experimental conditions, (Fig. 2e), estimated the capacity after $720 \mathrm{~min}$ to be $q_{e}=15.67 \mathrm{mEq} / 100 \mathrm{~g}$ and the adsorption rate of $k_{2}=0.002 \mathrm{mEq} / 100 \mathrm{~g}$ min using a $\mathrm{NaCl}$ concentration at $0.1 \mathrm{M}$. The Elovich model showed a high correlation coefficient (Fig. 2f) for natural zeolite form, describing a rapid initial adsorption of $a=2.54 \mathrm{mEq} / 100 \mathrm{~g}$ min and the number of sites available for adsorption of $b=0.39 \mathrm{mEq} / 100 \mathrm{~g}$ min. The results obtained from natural zeolite kinetic modelling (Table 5) were comparable with values report for adsorption of $\mathrm{Ni}^{2+}, \mathrm{Pb}^{2+}$ and $\mathrm{NH}_{4}^{+}$ions using clinoptilolite in terms of ion exchange adsorption behaviour reported by Argun (2008), Günay et al. (2007), and Nguyen and Tanner (1998). 

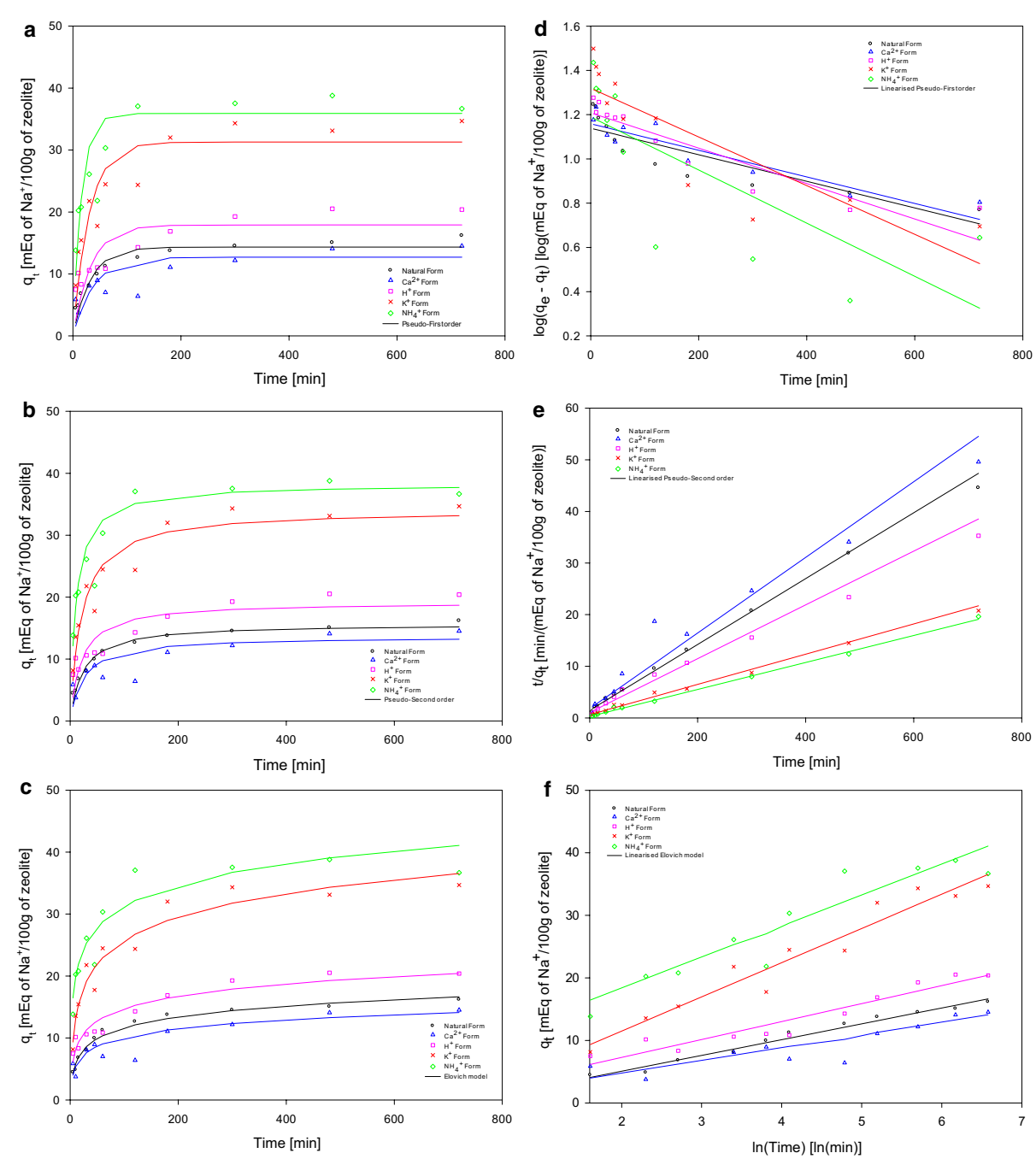

Fig. 2 Adsorbed amounts of $\mathrm{Na}^{+}$experimental, modelled and linear form of kinetic data for natural and treated zeolite materials. Initial $\mathrm{Na}^{+}$concentration $0.1 \mathrm{M}$ at pH 7, shaking speed of $300 \mathrm{rpm}$ at $25^{\circ} \mathrm{C}$ and solid-liquid ratio $50 \mathrm{~g} / \mathrm{L}$. The symbols are as follows: (circle) Natural zeolite form, (triangle) $\mathrm{Ca}^{2+}$ form, (square) $\mathrm{H}^{+}$form, (cross) $\mathrm{K}^{+}$form, (diamond) $\mathrm{NH}_{4}{ }^{+}$form. a, d Pseudo-First kinetic order. b, e Pseudo-Second kinetic order. c, f Elovich. Each data point is a mean of two replicates, which did not vary by more than $5 \%$

Natural zeolite was treated with a range of inorganic salts and acid solutions to modify its natural state. These treatments stages resulted in the migration of cations that were naturally contained in the zeolite framework for cations contained in the inorganic and acid treatments. Each treatment introduces only one type of cation that replaces the natural cations contained within the zeolite framework. The treated form of zeolite is known as homoionic (Inglezakis and Zorpas 2012; Wang et al. 2012). Figure 2 shows the experimental adsorption behaviour of $\mathrm{Na}^{+}$ions for different homoionic forms of treated zeolite, as well as the modelled kinetics. The experimental data and kinetic constants obtained are shown in Table 5 .

In Fig. 2, the $\mathrm{Na}^{+}$adsorption behaviour for each zeolite treatment is shown. Zeolite material in $\mathrm{Ca}^{2+}$ and $\mathrm{H}^{+}$form have an initial adsorption for the first 200 min of contact 


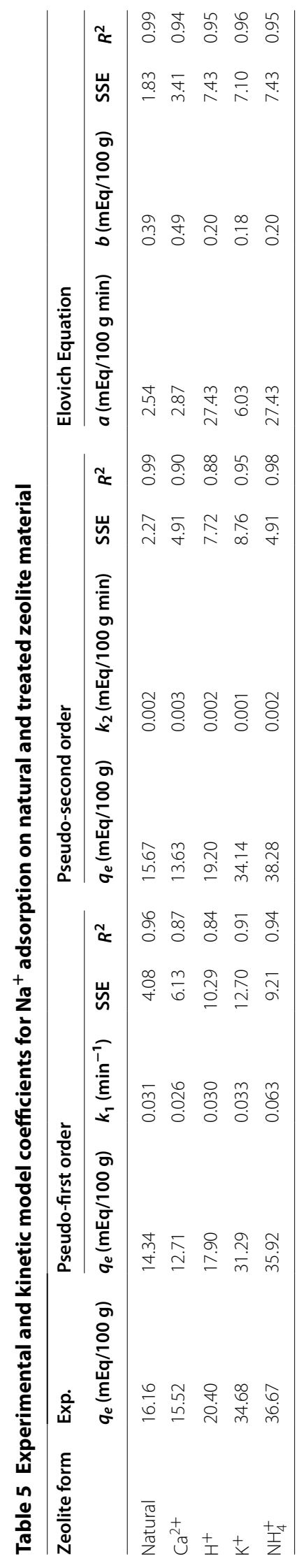


time with the $\mathrm{NaCl}$ solution at $0.1 \mathrm{M}$. After the rapid initial adsorption, a reduction of the kinetic process is observed from the $300 \mathrm{~min}$ until $720 \mathrm{~min}$ when adsorption rate is low. In comparison, zeolites treated with $\mathrm{KCl}$ and $\mathrm{NH}_{4} \mathrm{C}_{2} \mathrm{H}_{3} \mathrm{O}_{2}$ showed a much more rapid adsorption during the first $100 \mathrm{~min}$ of contact time followed by a reduction in adsorption kinetic for the following $200 \mathrm{~min}$. In addition, the final $\mathrm{Na}^{+}$adsorption after $720 \mathrm{~min}$ is greater for $\mathrm{K}^{+}$and $\mathrm{NH}_{4}{ }^{+}$zeolite forms than those observed for $\mathrm{Ca}^{2+}$ and $\mathrm{H}^{+}$ zeolite forms (Table 5).

Moreover, the adsorption of $\mathrm{Na}^{+}$for $\mathrm{K}^{+}$and $\mathrm{NH}_{4}{ }^{+}$zeolite forms after the first $100 \mathrm{~min}$ increased by 2.5-3 fold throughout the treatment using $\mathrm{KCl}$ and $\mathrm{NH}_{4} \mathrm{C}_{2} \mathrm{H}_{3} \mathrm{O}_{2}$ at $1 \mathrm{M}$. The experimental adsorption capacity of zeolite treated with $\mathrm{CaCl}_{2}$ and $\mathrm{HCl}$ solutions were found to be $q_{e}=15.52 \mathrm{mEq} / 100 \mathrm{~g}$ and $q_{e}=20.40 \mathrm{mEq} / 100 \mathrm{~g}$, after $720 \mathrm{~min}$ respectively. Treatments such as $\mathrm{KCl}$ and $\mathrm{NH}_{4} \mathrm{C}_{2} \mathrm{H}_{3} \mathrm{O}_{2}$ achieved an adsorption of $q_{e}=34.68 \mathrm{mEq} / 100 \mathrm{~g}$ and $q_{e}=36.67 \mathrm{mEq} / 100 \mathrm{~g}$. The adsorption capacity of $\mathrm{Na}^{+}$ions by $\mathrm{NH}_{4}{ }^{+}$zeolite form after 720 min was increased 2.3 fold when compared with $\mathrm{Ca}^{2+}$ zeolite form.

The kinetic models fitted the experimental data describing the ion exchange system for each treatment studied (Table 5; Fig. 2). The model that better describes the experimental data for all treatments is the pseudo-second kinetic order and the linearized form of the kinetic is shown in Fig. 2e. The pseudo-second order kinetic model was also the preferred model to describe the ion exchange and adsorption kinetics when clinoptilolite was used to remove lead, nickel and ammonium ions from solutions (Kocaoba et al. 2007; Nguyen and Tanner 1998; Vassileva and Voikova 2009).

The zeolite treatments have shown an improvement on the ion exchange process for adsorption of $\mathrm{Na}^{+}$ions for both adsorption rate and capacity values. The homoionic $\mathrm{NH}_{4}{ }^{+}$zeolite form treated with $\mathrm{NH}_{4} \mathrm{C}_{2} \mathrm{H}_{3} \mathrm{O}_{2}$ has enhanced the $\mathrm{Na}^{+}$adsorption process when compared with the natural zeolite. The $\mathrm{NH}_{4}{ }^{+}$zeolite form has a $\mathrm{Na}^{+}$adsorption capacity of $q_{e}=36.67 \mathrm{mEq} / 100 \mathrm{~g}$, while the $\mathrm{Na}^{+}$adsorption capacity of natural zeolite form is $q_{e}=16.16 \mathrm{mEq} / 100 \mathrm{~g}$. The experimental $\mathrm{Na}^{+}$adsorption for treated zeolite with $1 \mathrm{M} \mathrm{NH}_{4} \mathrm{C}_{2} \mathrm{H}_{3} \mathrm{O}_{2} 2.3$ folds the value determined for adsorption capacity on natural zeolite. The pseudo-second order kinetic model describes the behaviour obtained experimentally with a coefficient determination of $R^{2}=0.98$. The linearized form for $\mathrm{NH}_{4}^{+}$treated and natural zeolite are shown in Fig. 2e. The $\mathrm{Na}^{+}$adsorption rate determined by the pseudo-first order kinetic model and Elovich showed that is the highest among the natural and treated zeolite material with a value of $k_{1}=0.063 \mathrm{mEq} / 100 \mathrm{~g}$ min and $a=27.47 \mathrm{mEq} / 100 \mathrm{~g}$ min, respectively. Comparable results were reported by Wang et al. (2012), (Argun 2008) and Günay et al. (2007) for clinoptilolite material in which improvement in the adsorption of sodium, nickel and lead ions in solution was possible through the chemical treatment using acids and inorganic salts.

\section{Diffusion modelling of $\mathrm{Na}^{+}$using zeolite material}

In order to determine the diffusion mechanism of the adsorption kinetics of $\mathrm{Na}^{+}$ions by natural and treated zeolite material intra-particle model, film and pore diffusion equation were applied to the experimental data. In the ion exchange process, the adsorption of $\mathrm{Na}^{+}$ions may indeed be controlled by one or more steps, such as film and/or pore diffusion. Usually, film diffusion occurs quickly where ions migrate from the bulk solution 
to the surface of the zeolite particle creating a liquid film and attaining equilibrium with the available sites on the surface. Film diffusion is followed by the pore diffusion which is a slower process. Intra-particle diffusion was explored in order to determine the intra-particle diffusion rate and the effect of the thickness of the boundary layer on the adsorption of $\mathrm{Na}^{+}$ions for natural and treated zeolite materials (Table 6). The diffusion coefficients for film and pore were calculated to determine which diffusion process limited the kinetics of the ion exchange system for the adsorption of $\mathrm{Na}^{+}$ions (Table 6).

Figure 3 shows the linear representation of the intra-particle diffusion model for natural and treated zeolite. When experimental data is plotted a straight line should be identified in order to assure that the adsorption process of $\mathrm{Na}^{+}$ions is controlled by intra-particle diffusion only. However, experimental data shown in Fig. 3 exhibit multilinear plots, which indicates that the adsorption process is influenced by two or more steps. From Fig. 3, it is evidenced that the external adsorption is significant only in the early stages of $\mathrm{Na}^{+}$adsorption represented by the first linear sharper portion. The second linear adsorption is the gradual adsorption controlling the intra-particle diffusion.

The first straight portion of the plots in Fig. 3 are assumed to be related with macropore and mesopore diffusion. The second portion represents the micropore diffusion. The slope of the first segment correspond to the intra-particle diffusion constant rate $\left(k_{i}\right)$ and

Table 6 Intra-particle diffusion model, film and pore diffusion values of $\mathrm{Na}^{+}$ions for natural and treated zeolite material

\begin{tabular}{|c|c|c|c|c|c|}
\hline \multirow[t]{2}{*}{ Zeolite form } & \multicolumn{3}{|l|}{ Intra-particle diffusion } & \multirow{2}{*}{$\begin{array}{l}\text { Film diffusion } \\
D_{f}\left(\mathrm{~cm}^{2} / \mathrm{s}\right)\end{array}$} & \multirow{2}{*}{$\begin{array}{l}\text { Pore diffusion } \\
D_{p}\left(\mathrm{~cm}^{2} / \mathrm{s}\right)\end{array}$} \\
\hline & $k_{i}\left(\mathrm{mEq} / 100 \mathrm{~g}^{*} \mathrm{~min}^{1 / 2}\right)$ & $C(\mathrm{mEq} / 100 \mathrm{~g})$ & $R^{2}$ & & \\
\hline Natural & 1.262 & 1.40 & 0.99 & $2.96 \times 10^{-5}$ & $5.70 \times 10^{-5}$ \\
\hline $\mathrm{Ca}^{2+}$ & 0.43 & 4.23 & 0.82 & $2.66 \times 10^{-5}$ & $5.70 \times 10^{-5}$ \\
\hline $\mathrm{H}^{+}$ & 0.75 & 6.14 & 0.98 & $3.73 \times 10^{-5}$ & $5.70 \times 10^{-5}$ \\
\hline $\mathrm{K}^{+}$ & 1.792 & 7.69 & 0.93 & $4.23 \times 10^{-5}$ & $3.80 \times 10^{-5}$ \\
\hline $\mathrm{NH}_{4}^{+}$ & 2.37 & 10.71 & 0.94 & $2.01 \times 10^{-4}$ & $1.71 \times 10^{-4}$ \\
\hline
\end{tabular}

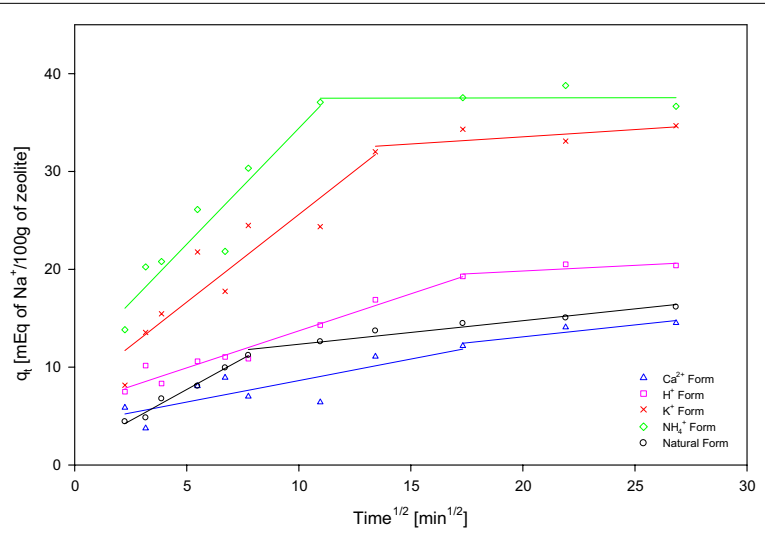

Fig. 3 Intra-particle diffusion model of $\mathrm{Na}^{+}$ions and experimental data for natural and treated zeolite materials. Initial $\mathrm{Na}^{+}$concentration $0.1 \mathrm{M}$ at pH 7, shaking speed of $300 \mathrm{rpm}$ at $25^{\circ} \mathrm{C}$ and solid-liquid ratio $50 \mathrm{~g} / \mathrm{L}$. The symbols are as follows: (circles) Natural zeolite form, (triangle) $\mathrm{Ca}^{2+}$ form, (square) $\mathrm{H}^{+}$form, (cross) $\mathrm{K}^{+}$form, (diamond) $\mathrm{NH}_{4}{ }^{+}$form 
the intercept $(C)$ of the first segment with the y-axis correspond to the measure of the boundary layer, which are reported in Table 6 for natural and treated zeolite. Nguyen et al. (2015) using Australian iron coated zeolite for adsorption of cadmium, chromium, copper, zinc and lead found that the intra-particle diffusion plot exhibit two linear plots. A fast step attributed to the external diffusion for the first $240 \mathrm{~min}\left(15 \mathrm{~min}^{1 / 2}\right)$ followed by slow step endorsed to the intra-particle diffusion till $1500 \mathrm{~min}\left(38 \mathrm{~min}^{1 / 2}\right)($ Nguyen et al. 2015).

Film and pore diffusion coefficients for particles of natural zeolite $(0.6-0.3 \mathrm{~mm})$ for experimental conditions were calculated as $2.96 \times 10^{-5}$ and $5.70 \times 10^{-5} \mathrm{~cm}^{2} / \mathrm{s}$, respectively. Often, when film diffusion has a greater value and internal diffusion has lower values the process is believed to be governed by particle diffusion. If pore diffusion coefficient results to be greater than film diffusion, the process is governed by film diffusion (Karthikeyan et al. 2010). Diffusion coefficients calculated for natural zeolite suggested that diffusion process is in some extent rate-limited by the film diffusion indicating the influence of the film diffusion. Film and pore diffusion coefficients were calculated through treatments detailed in Table 6. Film diffusion is not the single rate-limiting factor for treated zeolite. Although, film diffusion coefficients for $\mathrm{K}^{+}$and $\mathrm{NH}_{4}{ }^{+}$zeolite forms were smaller than those coefficients found for pore diffusion, which is in accordance with the intra-particle diffusion model.

\section{Maximum level of sodium adsorption for natural and treated exchangers}

Effective $\mathrm{Na}^{+}$ion adsorption capacity was studied in batch mode until no metal adsorption was observed in the system using natural and treated zeolite materials and $\mathrm{NaCl}$ solutions at $0.1 \mathrm{M}$. Zeolite and the corresponding solution systems had reached equilibrium within the first 5 days of contact time. Figure 4 shows the effective $\mathrm{Na}^{+}$adsorption for natural and treated zeolite as well as the overall percentage of $\mathrm{Na}^{+}$adsorption.

The natural zeolite material exhibited a capacity of $Q_{e}=22.04 \mathrm{mEq} / 100 \mathrm{~g}$ and $10.4 \%$ of $\mathrm{Na}^{+}$removed from the $\mathrm{NaCl}$ solution at $0.1 \mathrm{M}$ (Fig. 4). Zeolites in $\mathrm{Ca}^{2+}$ and $\mathrm{H}^{+}$form, showed similar $\mathrm{Na}^{+}$adsorption capacity observed on natural zeolite with values of $Q_{e}=20.89 \mathrm{mEq} / 100 \mathrm{~g}$ and $Q_{e}=26.41 \mathrm{mEq} / 100 \mathrm{~g}$, correspondingly. $\mathrm{K}^{+}$and $\mathrm{NH}_{4}{ }^{+}$zeolite forms were found to have higher adsorption capacity values for $\mathrm{Na}^{+}$ions,

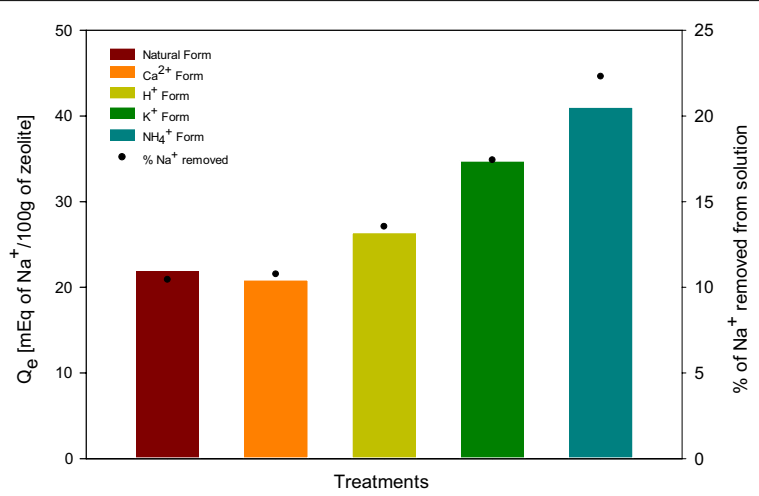

Fig. 4 Effect of zeolite treatment on the effective adsorption of $\mathrm{Na}^{+}$ions and the percentage of $\mathrm{Na}^{+}$ions removed. $\mathrm{Na}^{+}$concentration $0.1 \mathrm{M}$ at pH 7, shaking speed of $300 \mathrm{rpm}$ at $25^{\circ} \mathrm{C}$ and solid-liquid ratio of $50 \mathrm{~g} / \mathrm{L}$. Each data point is a mean of two replicates, which did not vary by more than $5 \%$ 
$Q_{e}=34.79 \mathrm{mEq} / 100 \mathrm{~g}$ and $Q_{e}=41.08 \mathrm{mEq} / 100 \mathrm{~g}$, respectively. Removal of $\mathrm{Na}^{+}$ions by the homoionic $\mathrm{K}^{+}$zeolite form reached $17.4 \%$, whilst $\mathrm{NH}_{4}{ }^{+}$zeolite form achieved a removal of $22.3 \%$. Maximum adsorption level of $\mathrm{Na}^{+}$ions using $\mathrm{NH}_{4}{ }^{+}$zeolite form was 1.8 times higher than the observed for natural zeolite form.

The results in Fig. 4 demonstrate that a zeolite material treated with $\mathrm{K}^{+}$or $\mathrm{NH}_{4}{ }^{+}$ions substantially increased the affinity for adsorption of $\mathrm{Na}^{+}$ions. All the results mentioned reveal that the capability of zeolite materials for the adsorption of $\mathrm{Na}^{+}$ions was in accordance with the order $\mathrm{NH}_{4}^{+}>\mathrm{K}^{+}>\mathrm{H}^{+}>\mathrm{Ca}^{2+}$ zeolite forms. Similar data have also been reported by Petrus and Warchoł (2003) whom confirmed that selectivity of clinoptilolite is weaker for divalent cations and predominantly determined by the hydrated radii of the cations that for $\mathrm{NH}_{4}{ }^{+}$ion is $3.3 \AA$, while $\mathrm{Ca}^{2+}$ ions is $4.2 \AA$.

Table 7 depicts the maximum $\mathrm{Na}^{+}$exchange capacity for the zeolite material for the natural and treated forms. Zeolite treatment using $\mathrm{NH}_{4} \mathrm{C}_{2} \mathrm{H}_{3} \mathrm{O}_{2}$ improved the adsorption of $\mathrm{Na}^{+}$ions when compared with the natural zeolite and achieved a $26.6 \%$ of the estimated maximum exchangeable capacity for zeolite material $(154 \mathrm{mEq} / 100 \mathrm{~g})$. These reported values are comparable with other studies in which adsorption of $\mathrm{Cu}^{2+}, \mathrm{Fe}^{3+}$, $\mathrm{Cr}^{3+}, \mathrm{Pb}^{2+}$ ions were tested using zeolites (Inglezakis et al. 2002). In this study, the average maximum level of exchange for zeolite reached $19 \%$ the total exchangeable capacity.

\section{Conclusions}

The natural ion exchange material is composed of $70 \%$ zeolite type minerals with a blend of $41 \%$ clinoptilolite, $29 \%$ mordenite and $30 \%$ quartz. The theoretical cation exchange capacity determined by the exchangeable cations held on the zeolite material $154 \mathrm{mEq} / 100 \mathrm{~g}$. The maximum $\mathrm{Na}^{+}$adsorption capacity observed for natural zeolite was $22.04 \mathrm{mEq} / 100 \mathrm{~g}$, which represents $14.3 \%$ of the exchangeable capacity determined XRF. The capacity of the zeolite material enhanced through treatment using $\mathrm{NH}_{4} \mathrm{C}_{2} \mathrm{H}_{3} \mathrm{O}_{2}$ at $1 \mathrm{M}$ concentration, attained a $\mathrm{Na}^{+}$adsorption capacity of $41.08 \mathrm{mEq} / \mathrm{g}$, which represents $26.6 \%$ of the theoretical exchangeable capacity of zeolite material. The adsorption of $\mathrm{Na}^{+}$ions by natural zeolite reached a capacity of $14.34 \mathrm{mEq} / 100 \mathrm{~g}$ after $720 \mathrm{~min}$ and an adsorption rate determined by a pseudo-second order kinetic model of $k_{2}=0.002 \mathrm{mEq} / 100 \mathrm{~g}$ min. Overall, homoionic treatment of zeolite materials have improved the $\mathrm{Na}^{+}$adsorption rate and capacity. $\mathrm{NH}_{4}{ }^{+}$zeolite form presented the largest sodium adsorption capacity and rate after $720 \mathrm{~min}$, which was calculated using a pseudosecond order kinetic model as $q_{e}=38.28 \mathrm{mEq} / 100 \mathrm{~g}$ and $k_{2}=0.002 \mathrm{mEq} / 100 \mathrm{~g} \mathrm{~min}$. The

Table 7 Maximum $\mathrm{Na}^{+}$exchangeable capacity for natural and treated zeolite

\begin{tabular}{lll}
\hline Treatments & $\begin{array}{l}\text { Experimental } \\
\boldsymbol{Q}_{\boldsymbol{e}}\left(\mathbf{m E q ~} \mathbf{1 0 0} \mathbf{~ g}^{-\mathbf{1}}\right)\end{array}$ & $\begin{array}{l}\text { \% of exchangeable capacity } \\
\%\end{array}$ \\
\hline Exchangeable capacity & 154 & - \\
Natural & 22.04 & 14.3 \\
$\mathrm{Ca}^{2+}$ & 20.89 & 13.5 \\
$\mathrm{H}^{+}$ & 26.41 & 17.1 \\
$\mathrm{~K}^{+}$ & 34.79 & 22.5 \\
$\mathrm{NH}_{4}^{+}$ & 41.08 & 26.6 \\
\hline
\end{tabular}


higher $\mathrm{Na}^{+}$adsorption by homoionic treated zeolite can be explained by the enrichment of cations on the natural material creating new available sites that may be accessible for incoming cations, hence higher efficiency in total adsorption is observed. Although homoionic treatment enhanced $\mathrm{Na}^{+}$adsorption, the maximum adsorption capacity observed is a portion of the theoretical capacity of the material. This could be explained by the existing impurities in the zeolite material that overestimate the theoretical capacity based on the exchangeable cations.

Intra-particle diffusion model showed that both natural and treated zeolite did not exhibit only intra-particle diffusion mechanism. Furthermore, modelling showed that film and pore diffusion occurred during the $\mathrm{Na}^{+}$adsorption process. Adsorption of $\mathrm{Na}^{+}$ ions onto natural and treated zeolite studied has shown that $\mathrm{Na}^{+}$adsorption capability was in accord with the order of zeolites in $\mathrm{NH}_{4}{ }^{+}>\mathrm{K}^{+}>\mathrm{H}^{+}>\mathrm{Ca}^{2+}$ form.

The treatment of zeolite material shows an increment on the $\mathrm{Na}^{+}$adsorption when it is compared with its natural form. Results indicate that by implementing homoionic treatments higher adsorption rates of $\mathrm{Na}^{+}$ions are achieved. This indicates that $\mathrm{Na}^{+}$ ions contained in CSG waters can be removed from the co-produced water reducing the environmental concerns due to high concentrations of sodium ions.

\section{Authors' contributions}

OS made substantial contributions to experimental design, analysis and writing, and was primarily responsible for experimental execution. BK, EG, KW and JC made substantial contributions to experimental design and to data interpretation and writing. BK provided the premise of the project, supporting data and material. All authors read and approved the final manuscript.

\section{Author details}

${ }^{1}$ School of Medical and Applied Sciences, CQUniversity, Rockhampton, QLD 4701, Australia. ${ }^{2}$ Arris Pty Ltd, Rockhampton, QLD, Australia.

\section{Acknowledgements}

This work is supported by a joint venture between Central Queensland University (CQUniversity) Office of Research $(\mathrm{O} \circ \mathrm{R})$ and Arris Pty Ltd, Australia.

\section{Competing interests}

The authors declare that they have no competing interests.

Received: 30 November 2015 Accepted: 15 April 2016

Published online: 10 May 2016

\section{References}

Alberti A, Armbruster T, Artioli G, Colella C, Galli E, Grice JD, Liebau F, Minato H, Nickel EH, Passaglia E (1997) Recommended nomenclature for zeolite minerals: report of the subcommittee on zeolites of the International Mineralogical Association, Commission on New Minerals and Mineral Names. Can Mineral 35:1571-1606

Argun ME (2008) Use of clinoptilolite for the removal of nickel ions from water: kinetics and thermodynamics. J Hazard Mater 150(3):587-595

Babak K, Rahim AA, Wahid SA, Balasundram SK, Afyuni M (2013) Sorption and desorption of zinc by clinoptilolite and clinoptilolite-tridymite. Malays J Soil Sci 17:69-83

Baker G, Slater S (2008) The increasing significance of coal seam gas in eastern Australia. In: Paper presented at the PESA Eastern Australasian Basins Symposium III, Sydney

Bektaş N, Kara S (2004) Removal of lead from aqueous solutions by natural clinoptilolite: equilibrium and kinetic studies. Sep Purif Technol 39(3):189-200

Chapman J, Regan F (2011) Sebacic and succinic acid derived plasticized PVC for the inhibition of biofouling in its initial stages. J Appl Biomater Biomech 9(3):176-184

Cincotti A, Lai N, Orrù R, Cao G (2001) Sardinian natural clinoptilolites for heavy metals and ammonium removal: experimental and modeling. Chem Eng J 84(3):275-282

Du Q, Liu S, Cao Z, Wang Y (2005) Ammonia removal from aqueous solution using natural Chinese clinoptilolite. Sep Purif Technol 44(3):229-234. doi:10.1016/j.seppur.2004.04.011

Günay A, Arslankaya E, Tosun I (2007) Lead removal from aqueous solution by natural and pretreated clinoptilolite: adsorption equilibrium and kinetics. J Hazard Mater 146(1):362-371. doi:10.1016/j.jhazmat.2006.12.034

Hamawand I, YusafT, Hamawand SG (2013) Coal seam gas and associated water: a review paper. Renew Sustain Energy Rev 22:550 
Huang H, Xiao X, Yan B, Yang L (2010) Ammonium removal from aqueous solutions by using natural Chinese (Chende) zeolite as adsorbent. J Hazard Mater 175(1):247-252. doi:10.1016/j.jhazmat.2009.09.156

Inglezakis VJ (2005) The concept of "capacity" in zeolite ion-exchange systems. J Colloid Interface Sci 281 (1):68-79. doi:10.1016/j.jcis.2004.08.082

Inglezakis VJ, Zorpas AA (2012) Handbook of natural zeolites. Bentham Science Publishers, Sharjah

Inglezakis VJ, Papadeas CD, Loizidou MD, Grigoropoulou HP (2001) Effects of pretreatment on physical and ion exchange properties of natural clinoptilolite. Environ Technol 22(1):75-82

Inglezakis VJ, Loizidou MD, Grigoropoulou HP (2002) Equilibrium and kinetic ion exchange studies of $\mathrm{Pb}^{2+}, \mathrm{Cr}^{3+}, \mathrm{Fe}^{3+}$ and $\mathrm{Cu}^{2+}$ on natural clinoptilolite. Water Res 36(11):2784-2792. doi:10.1016/S0043-1354(01)00504-8

Inglezakis VJ, Loizidou MM, Grigoropoulou HP (2004) lon exchange studies on natural and modified zeolites and the concept of exchange site accessibility. J Colloid Interface Sci 275(2):570-576. doi:10.1016/j.jcis.2004.02.070

Jackson R, Reddy K (2007) Geochemistry of coalbed natural gas (CBNG) Produced water in Powder River Basin, Wyoming: salinity and Sodicity. Water Air Soil Pollut 184(1):49-61. doi:10.1007/s11270-007-9398-9

Jones C, Vicente-Beckett V, Chapman J (2014) Heavy metal composition of turbid river waters associated with coal mineaffected water releases in the Fitzroy River Basin (Central Queensland)

Karthikeyan S, Sivakumar B, Sivakumar N (2010) Film and pore diffusion modeling for adsorption of reactive red 2 from aqueous solution on to activated carbon prepared from bio-diesel industrial waste. J Chem 7(S1):S175-S184

Kele B (2005) Onsite wastewater treatment and reuse using recirculatory evapotranspiration channels in regional Queensland. (Master degree), Central Queensland University, Queensland, Australia

Kele B (2015) The use of selected volcanic rocks for the sustainable treatment of wastewater (unpublished doctoral dissertation). Central Queensland University, Queensland

Kinnon ECP, Golding SD, Boreham CJ, Baublys KA, Esterle JS (2010) Stable isotope and water quality analysis of coal bed methane production waters and gases from the Bowen Basin, Australia. Int J Coal Geol 82(3):219-231. doi:10.1016/j. coal.2009.10.014

Kocaoba S, Orhan Y, AkyüzT (2007) Kinetics and equilibrium studies of heavy metal ions removalby use of natural zeolite. Desalination 214(1):1-10. doi:10.1016/j.desal.2006.09.023

Kumar S, Jain S (2013) History, introduction, and kinetics of ion exchange materials. J Chem. doi:10.1155/2013/957647

Lehto J, Harjula R (1995) Experimentation in ion exchange studies-the problem of getting reliable and comparable results. React Funct Polym 27(2):121-146. doi:10.1016/1381-5148(95)00038-H

Nghiem LD, Ren T, Aziz N, Porter I, Regmi G (2011) Treatment of coal seam gas produced water for beneficial use in Australia: a review of best practices. Desalin Water Treat 32(1-3):316-323. doi:10.5004/dwt.2011.2716

Nguyen M, Tanner C (1998) Ammonium removal from wastewaters using natural New Zealand zeolites. N Z J Agric Res 41(3):427-446

Nguyen TC, Loganathan P, Nguyen TV, Vigneswaran S, Kandasamy J, Naidu R (2015) Simultaneous adsorption of Cd, Cr, $\mathrm{Cu}, \mathrm{Pb}$, and Zn by an iron-coated Australian zeolite in batch and fixed-bed column studies. Chem Eng J 270:393-404

Oren AH, Kaya A (2006) Factors affecting adsorption characteristics of $\mathrm{Zn}^{2+}$ on two natural zeolites. J Hazard Mater 131(1-3):59

Pabalan RT, Bertetti FP (2001) Cation-exchange properties of natural zeolites. Rev Miner Geochem 45(1):453-518. doi:10.2138/rmg.2001.45.14

Petrus R, Warchoł J (2003) Ion exchange equilibria between clinoptilolite and aqueous solutions of $\mathrm{Na}^{+} / \mathrm{Cu}^{2+}, \mathrm{Na}^{+} / \mathrm{Cd}^{2+}$ and $\mathrm{Na}^{+} / \mathrm{Pb}^{2+}$. Microporous Mesoporous Mater 61(1):137-146. doi:10.1016/S1387-1811(03)00361-5

Regan F, Jones L, Chapman J (2013) Monitoring criteria for priority chemicals leading to emission factors. In: E. S. P. 2007-2013 (ed) 2007-WQ-LS-1-S1. Environmental Protection Agency, Wexford

Rengasamy P. Marchuk A (2011) Cation ratio of soil structural stability (CROSS). Soil Res 49(3):280-285

Semmens MJ, Martin WP (1988) The influence of pretreatment on the capacity and selectivity of clinoptilolite for metal ions. Water Res 22(5):537-542. doi:10.1016/0043-1354(88)90052-8

Sprynskyy M, Golembiewski R, Trykowski G, Buszewski B (2010) Heterogeneity and hierarchy of clinoptilolite porosity. J Phys Chem Solids 71(9):1269-1277. doi:10.1016/j.jpcs.2010.05.006

Stylianou MA, Hadjiconstantinou MP, Inglezakis VJ, Moustakas KG, Loizidou MD (2007) Use of natural clinoptilolite for the removal of lead, copper and zinc in fixed bed column. J Hazard Mater 143(1):575-581. doi:10.1016/j. jhazmat.2006.09.096

Taulis M, Milke M (2007) Coal seam gas water from Maramarua, New Zealand: characterisation and comparison to United States Analogues. J Hydrol 46(1):1-17

Townsend RP (1986) lon exchange in zeolites: some recent developments in theory and practice. Stud Surf Sci Catal 28:273-282. doi:10.1016/S0167-2991(09)60883-1

Vassileva P, Voikova D (2009) Investigation on natural and pretreated Bulgarian clinoptilolite for ammonium ions removal from aqueous solutions. J Hazard Mater 170(2):948-953. doi:10.1016/j.jhazmat.2009.05.062

Wang S, Peng Y (2010) Natural zeolites as effective adsorbents in water and wastewater treatment. Chem Eng J 156(1):11-24. doi:10.1016/j.cej.2009.10.029

Wang X, Ozdemir O, Hampton MA, Nguyen AV, Do DD (2012) The effect of zeolite treatment by acids on sodium adsorption ratio of coal seam gas water. Water Res 46(16):5247-5254. doi:10.1016/j.watres.2012.07.006

Weatherley L, Miladinovic N (2004) Comparison of the ion exchange uptake of ammonium ion onto New Zealand clinoptilolite and mordenite. Water Res 38(20):4305-4312

Zhao H, Vance GF, Ganjegunte GK, Urynowicz MA (2008) Use of zeolites for treating natural gas co-produced waters in Wyoming, USA. Desalination 228(1):263-276. doi:10.1016/j.desal.2007.08.014

Zhao H, Vance GF, Urynowicz MA, Gregory RW (2009) Integrated treatment process using a natural Wyoming clinoptilolite for remediating produced waters from coalbed natural gas operations. Appl Clay Sci 42(3):379-385. doi:10.1016/j.clay.2008.03.007 